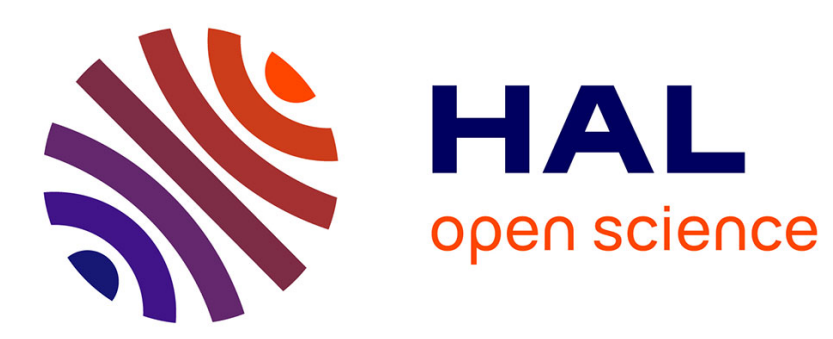

\title{
First satellite ozone distributions retrieved from nadir high-resolution infrared spectra
}

Solène Turquety, Juliette Hadji-Lazaro, Cathy Clerbaux

\section{To cite this version:}

Solène Turquety, Juliette Hadji-Lazaro, Cathy Clerbaux. First satellite ozone distributions retrieved from nadir high-resolution infrared spectra. Geophysical Research Letters, 2002, 29 (24), pp.2198. 10.1029/2002gl016431 . insu-03518143

\section{HAL Id: insu-03518143 \\ https://hal-insu.archives-ouvertes.fr/insu-03518143}

Submitted on 9 Jan 2022

HAL is a multi-disciplinary open access archive for the deposit and dissemination of scientific research documents, whether they are published or not. The documents may come from teaching and research institutions in France or abroad, or from public or private research centers.
L'archive ouverte pluridisciplinaire HAL, est destinée au dépôt et à la diffusion de documents scientifiques de niveau recherche, publiés ou non, émanant des établissements d'enseignement et de recherche français ou étrangers, des laboratoires publics ou privés. 


\title{
First satellite ozone distributions retrieved from nadir high-resolution infrared spectra
}

\author{
Solène Turquety, Juliette Hadji-Lazaro, and Cathy Clerbaux \\ Service d'Aéronomie, Institut Pierre-Simon Laplace, Paris, France \\ Received 10 October 2002; revised 8 November 2002; accepted 15 November 2002; published 26 December 2002.
}

[1] The Interferometric Monitor for Greenhouse Gases (IMG) on board the Japanese ADEOS platform provided the first high resolution atmospheric spectra allowing the simultaneous measurement of several IR absorbing species, including ozone. The paper describes the retrieval of total column ozone fields from nadir radiances, using an inversion algorithm developed for the Infrared Atmospheric Sounding Interferometer (IASI). The accuracy and sensitivity of the retrieved concentrations are assessed. The global distributions obtained from the available IMG/ADEOS Level $1 \mathrm{C}$ data are shown to be in good agreement with the TOMS/ADEOS (Total Ozone Mapping Spectrometer) Level 2 measurements. INDEX TERMS: 0394 Atmospheric Composition and Structure: Instruments and techniques; 1610 Global Change: Atmosphere (0315, 0325); 1640 Global Change: Remote sensing. Citation: Turquety, S., J. Hadji-Lazaro, and C. Clerbaux, First satellite ozone distributions retrieved from nadir high-resolution infrared spectra, Geophys. Res. Lett., 29(24), 2198, doi:10.1029/2002GL016431, 2002.

\section{Introduction}

[2] A constant monitoring of the global distribution of ozone is of major importance for both meteorological and climatological concerns. Since 1978, high quality total columns of ozone are provided on a daily basis by the Total Ozone Mapping Spectrometer (TOMS) [Heath et al., 1975], present on board Nimbus-7 (1978-1993), Meteor-3 (19911994), ADEOS (1996-1997) and Earth Probe (since 1996), and, more recently, by the Global Ozone Monitoring Experiment (GOME), launched in 1995 aboard ERS-2 [Burrows et al., 1999]. These two instruments measure the backscattered solar UV-visible radiation. Total ozone amounts are also provided by the High resolution Infrared Radiation Sounder (HIRS) component of the Tiros-N Operational Vertical Sounder (TOVS) series aboard NOAA's satellites [Smith et al., 1979] which measures the Earth's thermal infrared (IR) radiation emitted at $9.7 \mu \mathrm{m}$. The principal advantage of this spectral range is that it allows retrievals in the Earth's shadow or polar night regions. Future missions will provide simultaneous measurements from UV-visible and high-resolution IR instruments present on the same platform with, for instance, the Ozone Monitoring Instrument (OMI) [Laan et al., 2001] and the Tropospheric Emission Spectrometer (TES) [Beer et al., 2001] on board EOS-AURA (due for launch in 2004), and GOME-2 and the Infrared Atmospheric Sounding Interferometer (IASI) [Cayla and Javelle, 1995] on board METOP (due for launch in 2005). The coupled use of the two spectral regions will enable day and night observations with an improved vertical resolution. Simultaneous IR and UV nadir measurements, recorded by the Interferometric Monitor for Greenhouse Gases (IMG) [Kobayashi et al., 1999] and TOMS on board ADEOS, are currently available. In this paper, an accurate total ozone retrieval from IR nadir radiances is presented. The associated inversion error and sensitivity are discussed and the global IMG/ADEOS $\mathrm{O}_{3}$ distributions are compared to the total columns provided by TOMS/ADEOS.

\section{Ozone Retrieval}

\subsection{Infrared Measurements}

[3] The IMG instrument was launched in August 1996 on board the Japanese ADEOS platform and sent information until the failure of ADEOS due to the destruction of the solar paddle, in June 1997. It recorded the Earth's thermal radiation between 600 and $3030 \mathrm{~cm}^{-1}$ in a nadir-viewing geometry, providing the first high resolution atmospheric spectra (spectral resolution $\sim 0.1 \mathrm{~cm}^{-1}$ after apodization), and thereby allowing the measurement of several IR absorbing species. Ozone concentrations are retrieved from the intense $v_{3}$ absorption band $\left(980-1080 \mathrm{~cm}^{-1}\right)$, represented in Figure 1 .

\subsection{Inversion Method}

[4] The inversion algorithm based on neural network (NN) techniques described in Hadji-Lazaro et al. [1999, 2001], developed for the IASI instrument and already used for the retrieval of CO from IMG data, has been adapted to the derivation of the total column of ozone. $\mathrm{NN}$ techniques were chosen for their ability to perform statistical modelization of very complicated non-linear transfer functions, their adaptability and their efficiency in operational phase - properties required for a real-time processing of satellite data. A coherence criterion has been added to the original scheme in order to access the quality of the retrievals. The inputs to the algorithm have been chosen among the Level 1 radiances and Level 2 temperature measurements providing relevant information about ozone and the state of the atmosphere. Spectral windows corresponding to strong $\mathrm{O}_{3}$ absorption lines but minimizing the contribution from interfering gases have been isolated [Clerbaux et al., 1998]. Among the 148 radiance channels selected, 146 have been used as input for the network, and the two remaining (hereafter referred to as test radiances) have been kept to test the algorithm's internal consistency. Further information has been included by means of the associated surface temperature and atmospheric temperature profile [Clerbaux et al., 1999], which will be operationally retrieved during the IASI mission. From these input data, the $\mathrm{NN}$ calculates the total column $\mathrm{O}_{3}$, together with the two test radiances. 


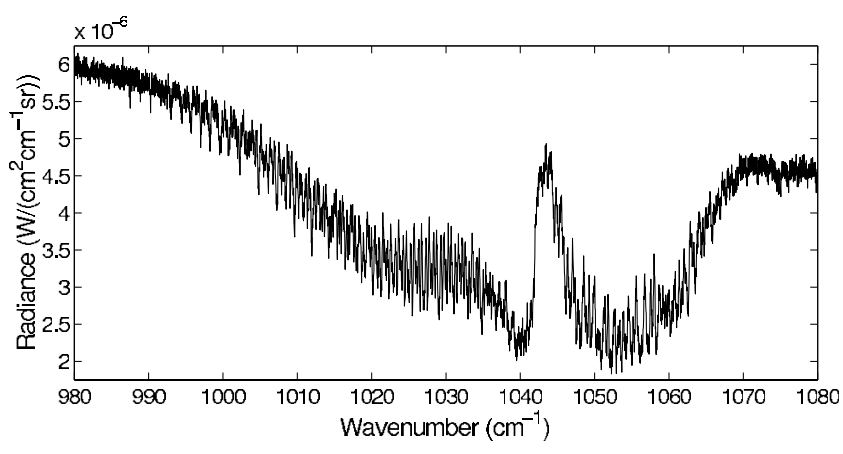

Figure 1. Radiance spectrum recorded by the IMG instrument on April 1, 1997 at $36.8^{\circ} \mathrm{W}, 40.3^{\circ} \mathrm{N}$ in the 980-1080 $\mathrm{cm}^{-1}$ spectral range, corresponding to the intense $\nu_{3} \mathrm{O}_{3}$ absorption band.

[5] The parameters of the NN have been determined during a calibration - or training - phase which required a set of well known examples. Therefore, spectra have been simulated using the Line-By-Line Radiative Transfer Model (LBLRTM) [Clough et al., 1995] at $0.5 \mathrm{~cm}^{-1}$ spectral resolution (characteristic of IASI) for cloud-free and aerosol-free conditions. As input to this code, we have used $\mathrm{O}_{3}$ mixing ratio profiles from the tropospheric chemistry-transport model MOZART (Model for OZone and Related Tracers) [Brasseur et al., 1998] connected to UGAMP climatologies [ $\mathrm{Li}$ and Shine, 1995] above the tropopause, along with temperature profiles extracted from the European Center for Medium-Range Weather Forecasts (ECMWF) analysis, and the Air Force Geophysics Laboratory (AFGL) standard atmosphere US 1976 profiles for the other absorbing species. The emissivity has been kept constant and set to a mean value of 0.9813 , estimated from values provided by Wilber et al. [1999]. In order to improve the generalization capacity of the algorithm, examples have been selected to constitute a dataset homogeneously representative of situations that the algorithm will have to process in operational phase. The instrumental noise has been accounted for by adding a random noise to the simulated spectra for half of the examples.

\section{Results}

\subsection{Analysis of Simulated Data}

[6] The performance of the inversion is evaluated on a test data set composed of simulations not learned by the NN. The absolute value of the error between retrieved and desired total $\mathrm{O}_{3}$ concentrations, $|\Delta \mathrm{C}|$, is smaller than $5 \%$ for more than $99 \%$ of the cases, with a mean value of $1.2 \%$. For the test radiances, $|\Delta R| \leq 5 \%$ for more than $97 \%$ of the cases, with a mean value of $1.1 \%$. The largest $|\Delta R|$, generally associated to large $|\Delta C|$, are encountered for situations which are not represented or are under-represented in the training dataset (e.g. extremely low surface temperatures or $\mathrm{O}_{3}$ concentrations), hereafter referred to as extreme cases.

[7] To access the performance reached, the sensitivity of the instrument and the algorithm to the main sources of uncertainty is investigated using a method of perturbation [Rodgers, 1990].

[8] The sensitivity of the instrument to the ozone vertical distribution is described by an analysis of Jacobians
[Cheruy et al., 1995], and the calculation of the averaging kernel then allows the characterization of the sensitivity of both the instrument and the algorithm [Clerbaux et al., 2001]. Figure 2 shows the results obtained for the standard atmosphere US 1976 ozone profile. A similar behavior is observed for all the well-represented cases studied. The Jacobians - shown for one channel-reach a maximum in the free troposphere, and decrease to almost zero above 35 $\mathrm{km}$ and below $2 \mathrm{~km}$, with relatively low values between 2 and $5 \mathrm{~km}$. The low sensitivity of the nadir measurements to concentrations in the first kilometers has already been noted in the case of CO [Hadji-Lazaro et al., 1999], and will induce an error on the retrieved total column. The averaging kernel also shows a maximum sensitivity in the free troposphere and low values below $5 \mathrm{~km}$, but the sensitivity remains large throughout the stratosphere, where the $\mathrm{O}_{3}$ concentration is large enough to compensate the lower sensitivity of the instrument. The main uncertainty comes from the contribution of the boundary layer and the upper stratosphere, where the information on $\mathrm{O}_{3}$ is provided through the training dataset (the a priori knowledge). The error induced is estimated at 4\% (15 DU) for well-represented cases, and can reach up to $15 \%$ for extreme cases.

[9] A gain calculation [Rodgers, 1990] allows the analysis of the sensitivity of the algorithm to a perturbation of the input elements. The radiances are randomly perturbed using the noise characteristics expected for IASI, i.e. noise level $<5 \cdot 10^{8}$ $\mathrm{W} /\left(\mathrm{cm}^{2} \mathrm{~cm}^{-1} \mathrm{sr}\right)$ (http://smsc.cnes.fr/IASI/index.htm), and the temperatures are perturbed using a IASI temperature error covariance matrix (P. Prunet, personal communication): error $<0.2 \mathrm{~K}$ at the surface, $\sim 0.9-1.5 \mathrm{~K}$ in the troposphere and $\sim 1.5-3 \mathrm{~K}$ in the stratosphere. It is found that an inversion error of $\sim 0.5 \%$ on the $\mathrm{O}_{3}$ retrieval is induced by the radiometric noise, and of $\sim 1.4 \%$ by uncertainties on the temperatures provided. Both $|\Delta R|$ and $|\Delta C|$ strongly increase with the magnitude of the perturbations applied.

[10] The capability of the test radiances to filter the nonreliable data has been checked. After filtering using a 5\%
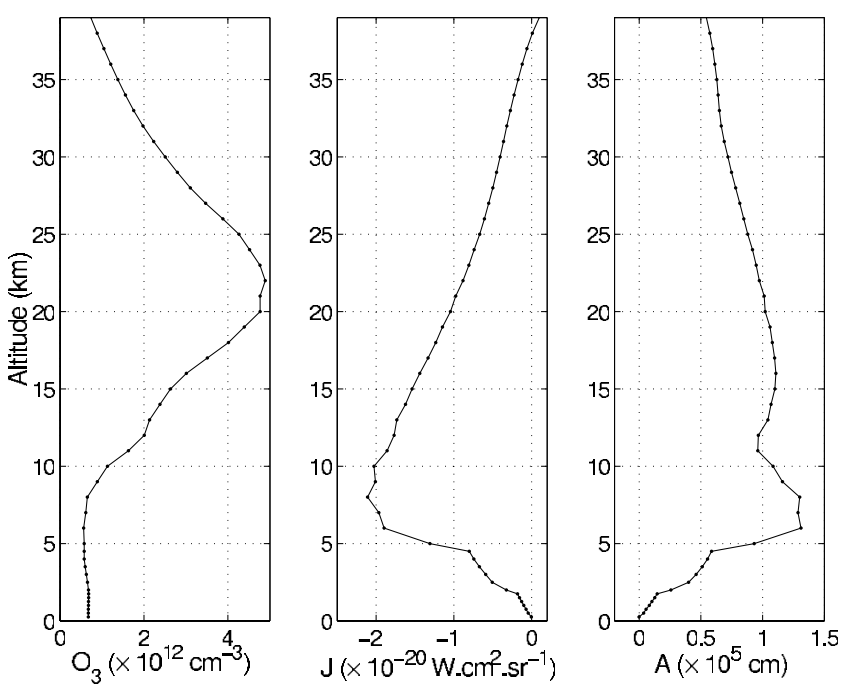

Figure 2. Jacobian (middle) at $1007 \mathrm{~cm}^{-1}$ and averaging kernel (right) characterizing the inversion of the total column $\mathrm{O}_{3}$, calculated using a $100 \%$ perturbation of the standard atmosphere US $1976 \mathrm{O}_{3}$ profile (left). 
threshold on $|\Delta R|$, the global averaged relative accuracy on the $\mathrm{O}_{3}$ retrieval is estimated at $6 \%$.

\section{Analysis of the IMG/ADEOS Data}

[11] The algorithm has been applied to the analysis of the IMG Level $1 \mathrm{C}$ data. The IMG spectra have been converted to IASI-like spectra by convolution with the IASI instrumental function [Camy-Peyret et al., 2001], and then entered to the $\mathrm{NN}$ together with the corresponding surface temperatures, calculated from the spectra, and the colocated ECMWF temperature profiles.

[12] As expected, the largest $|\Delta \mathrm{R}|$ are found to correspond to areas characterized by extreme emissivities, including clouds, deserts, shrub land and snow/ice covered areas (e.g. Sahara, Middle East, Siberia). This is due to the fact that the NN has been trained using examples simulated for clear-sky conditions, with a mean emissivity. A relatively large $|\Delta R|$ is also obtained for situations already identified in simulated data: low quality measurements (low signal/ noise), extreme surface temperatures or total $\mathrm{O}_{3}$ amounts. As described in the previous section, the most accurate data were selected by removing the cases for which $|\Delta \mathrm{R}| \geq 5 \%$.

[13] Four high quality IMG periods were analyzed: December 26-28 1996, January 25-28 1997, April 1-10 1997, and June 16-19 1997. The $\mathrm{O}_{3}$ distribution obtained for April 1997 after filtering (46\% of the cases removed) is shown in Figure 3. As expected, the largest columns are observed at high latitudes and over the polluted areas of the Northern hemisphere, whereas the lowest ones are located in the tropics.

\section{Comparison with the TOMS/ADEOS Data}

[14] The TOMS/ADEOS Level 2 data are used to validate the total $\mathrm{O}_{3}$ retrievals. Over the four periods analyzed, 7792 co-located IMG and TOMS measurements $\left( \pm 0.5^{\circ}, \pm 2\right.$ seconds, TOMS cloud-cover fractions $\leq 20 \%$ ) are compared. They correspond to day-time IMG observations, which are

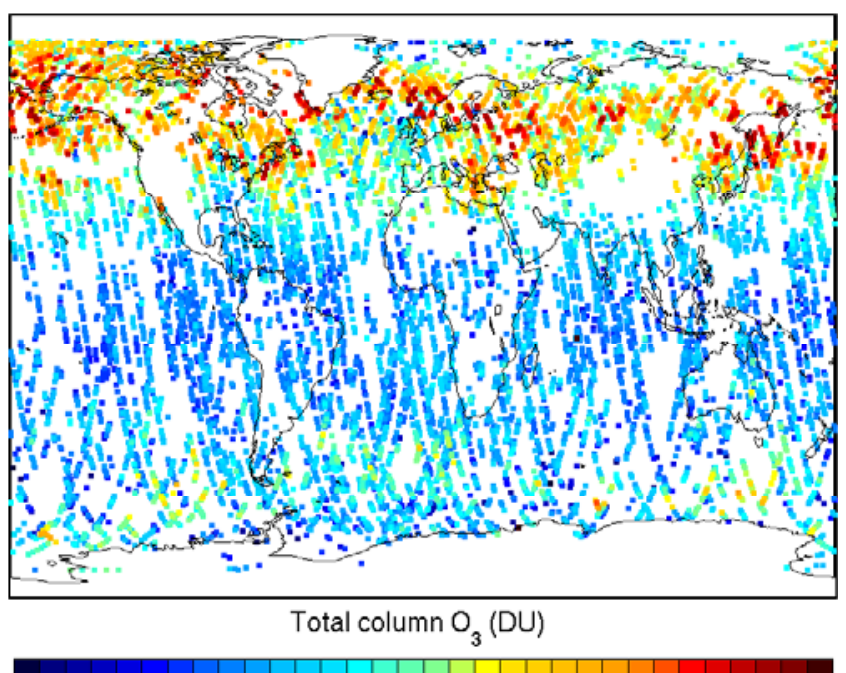

200220240260280300320340360380400420440460480500

Figure 3. Global $\mathrm{O}_{3}$ distribution for April 1-10, 1997, retrieved from IMG/ADEOS Level 1C spectra (after filtering).

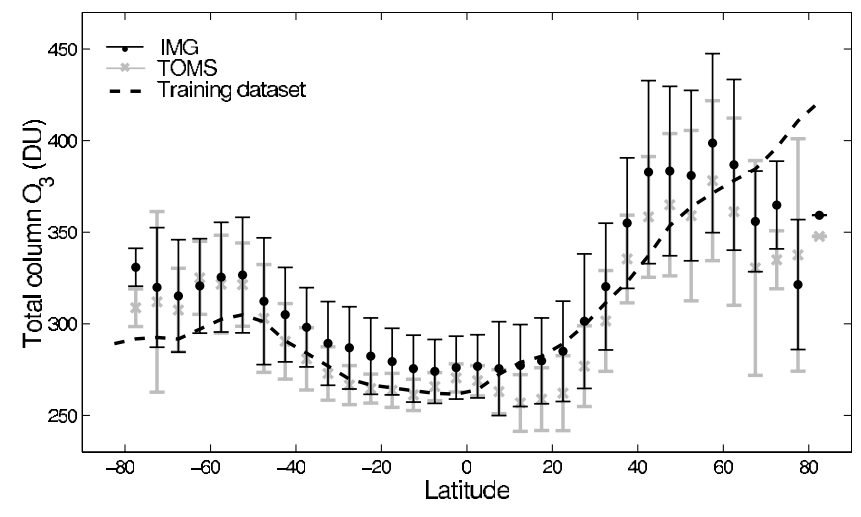

Figure 4. Total $\mathrm{O}_{3}$ derived from co-located IMG/ADEOS and TOMS/ADEOS measurements, and from the $\mathrm{O}_{3}$ training set, zonally averaged over the four periods analyzed (with associated standard deviations).

less accurate than night-time ones. The accuracy of TOMS total $\mathrm{O}_{3}$ is estimated at about $3 \%$ by comparison with ground-based measurements [Krueger and Jaross, 1999].

[15] Globally, the agreement between the two distributions is very good for all the periods studied, with a correlation of 0.86 and an rms error of 27 DU $(\sim 10 \%)$. The co-located $\mathrm{O}_{3}$ distributions averaged over $5^{\circ}$ latitude bands, shown in Figure 4, highlight an apparent positive bias between the two series of measurements, with larger differences at high latitudes and in the $10^{\circ}-40^{\circ}$ regions, especially in the Northern hemisphere. A more detailed comparison shows that the variability of the IMG retrievals is generally slightly larger than that of TOMS data, except at high latitudes where the latter increases.

[16] The most significant contribution to the bias observed comes from the different observation methods used. Indeed, the two instruments are characterized by different weighting functions, and therefore have different sensitivities to the vertical atmospheric layers: the maximum sensitivity is reached in the stratosphere for TOMS and in the free troposphere for IMG. As a result, the tropospheric contribution above the boundary layer is larger for IMG, which explains the larger bias at mid-latitudes and the larger variability of the IMG distributions. In addition, local differences can be due to partially cloudy pixels remaining after the filtering process and to observations not exactly co-located. The larger differences at high latitudes are attributed to the lower accuracy of TOMS at larger scan angles. In the tropics, an over-estimation of the IMG total columns partly occurs due to an insufficient representation of the lowest total $\mathrm{O}_{3}$ amounts $(\leq 250 \mathrm{DU})$ in the training set.

\section{Conclusions}

[17] This paper presents the first global distributions of ozone retrieved from IMG/ADEOS measurements using the IASI trace-gas algorithm. The combined retrieval of total ozone and a coherence criterion (test radiances) allows the reliability of the results to be checked. The $\mathrm{O}_{3}$ distributions obtained after filtering are found to be in good agreement with the co-located TOMS/ADEOS total columns. The standard accuracy of the retrievals is estimated at $6 \%$, 
compared with the $3 \%$ value estimated for TOMS. However, IMG presents the advantage of providing good quality day and night measurements at all latitudes and of being more sensitive to the free troposphere.

[18] Advanced versions of the algorithm are currently under development to improve the treatment of the surface parameters, and retrieve information on the $\mathrm{O}_{3}$ vertical distribution. The possibility of obtaining accurate global Level 3 distributions by combining measurements from different instruments (IMG and TOMS on board ADEOS or IASI and GOME-2 on board METOP) using data assimilation techniques is also being investigated.

[19] Acknowledgments. The authors thank D. Hauglustaine for providing the outputs of the MOZART model, T. Clough for the LBLRTM radiative transfer model, and P. Prunet for providing the IASI temperature error covariance matrix. We acknowledge IMGDIS/ERSDAC for providing the IMG Level 1 data, and the NASA Goddard Space Flight Center's Distributed Active Archive Center (http://daac.gsfc.nasa.gov/) for providing the TOMS Level 2 data. We also thank C. Rodgers for helpful discussions on the error analysis and J.-F. Lamarque for his help using the TOMS Level 2 data. This work was undertaken in the framework of the ISSWG (IASI Sounding Science Working Group) activities under the auspices of EUMETSAT (European Organization for the Exploitation of Meteorological Satellites) and CNES (Centre National d'Études Spatiales).

\section{References}

Beer, R. T., A. Glavich, and D. M. Rider, Tropospheric emission spectrometer for the Earth Observing System's Aura satellite, Appl. Opt., 40, 2356-2367, 2001.

Brasseur, G. P., D. A. Hauglustaine, S. Walters, P. J. Rasch, J.-F. Müller, C. Granier, and X. X. Tie, MOZART, a global chemical transport model for ozone and related chemical tracers, 1, Model description, J. Geophys. Res., 103, 28,265-28,289, 1998.

Burrows, J. P., et al., The Global Ozone Monitoring Experiment (GOME): Mission Concept and First Scientific Results, J. Atmos. Sci., 56, $151-$ $175,1999$.

Camy-Peyret, C., S. Payan, and C. Claveau, The instrumental spectral response function for IASI level 1C: A contribution of LPMA to the ISSWG activities, Tech. Rep., 28 pp., CNES/EUMETSAT, Paris, 2001.

Cayla, F., and P. Javelle, IASI instrument overview, Int. Soc. Opt. Eng., Proc. SPIE, 2583, 271-281, 1995.

Cheruy, F., N. A. Scott, R. Armante, B. Tournier, and A. Chedin, Contribution to the development of radiative transfer models for high spectral resolution observations in the infrared, J. Quant. Spectrosc. Radiat Transfer, 53, 597-611, 1995.
Clerbaux, C., P. Chazette, J. Hadji-Lazaro, G. Mégie, J.-F. Müller, and S. A. Clough, Remote sensing of $\mathrm{CO}, \mathrm{CH}_{4}$, and $\mathrm{O}_{3}$ using a spaceborne nadirviewing interferometer, J. Geophys. Res., 103, 18,999-19,013, 1998.

Clerbaux, C., J. Hadji-Lazaro, S. Payan, C. Camy-Peyret, and G. Mégie, Retrieval of CO columns from IMG/ADEOS spectra, IEEE Transactions on Geoscience and Remote Sensing, 37, 1657-1661, 1999.

Clerbaux, C., J. Hadji-Lazaro, D. Hauglustaine, G. Mégie, B. V. Khattatov, and J. F. Lamarque, Assimilation of carbon monoxide measured from satellite in a three-dimensional chemical-transport model, J. Geophys. Res., 106, 15,385-15,394, 2001.

Clough, S. A., M. J. Iacono, and J.-L. Moncet, Line-by-line calculation of atmospheric fluxes and cooling rates: 2. Application to carbon dioxide, ozone, methane, nitrous oxide and halocarbons, J. Geophys. Res., 100, $16,519-16,535,1995$.

Hadji-Lazaro, J., C. Clerbaux, and S. Thiria, An inversion algorithm using neural networks to retrieve atmospheric $\mathrm{CO}$ total columns from highresolution nadir radiances, J. Geophys. Res., 104, 23,841-23,854, 1999.

Hadji-Lazaro, J., C. Clerbaux, P. Couvert, P. Chazette, and C. Boone, Cloud filter for CO retrieval from IMG infrared spectra using ECMWF temperatures and POLDER cloud data, Geophys. Res. Lett., 28, 2397-2400, 2001.

Heath, D. F., A. J. Krueger, H. R. Roeder, and B. D. Henderson, The solar backscatter ultraviolet and total ozone mapping spectrometer (SBUV/ TOMS) for Nimbus G, Opt. Eng., 14, 323-331, 1975.

Kobayashi, H., A. Shimota, K. Kondo, E. Okumura, Y. Kameda, H. Shimoda, and T. Ogawa, Development and evaluation of the interferometric monitor for greenhouse gases: a high-throughput Fourier-transform infrared radiometer for nadir Earth observation, Appl. Opt., 38, 6801-6807, 1999.

Krueger, A. J., and G. Jaross, TOMS/ADEOS Instrument Characterization, IEEE Trans, Geosci. Remote Sens., 37, 1543-1549, 1999.

Laan, E., D. de Winter, J. de Vries, P. F. Levelt, G. H. van den Oord, A. Malkki, G. W. Leppelmeier, and E. Hilsenrath, Toward the use of the Ozone Monitoring Instrument (OMI), Proc. SPIE, 4540, 270-277, 2001.

Li, D., and K. P. Shine, A 4-dimensional ozone climatology for UGAMP models, Internal Report No. 35, U.G.A.M.P., 1995.

Rodgers, C. D., Characterization and error analysis of profiles retrieved from remote sounding measurements, J. Geophys. Res., 95, 55875595, 1990 .

Smith, L. M., H. M. Woolf, C. M. Hayden, D. Q. Wark, and L. M. McMillin, The TIROS-N Operational Vertical Sounder, Bull. Amer. Meteor. Soc., 60, 1177-1187, 1979.

Wilber, A. C., D. P. Kratz, and S. K. Gupta, Surface emissivity maps for use in satellite retrievals of longwave radiation, Tech. Publ. NASA/TP-1999209362, 35 pp., Nat. Aeron. and Space Adm., 1999.

S. Turquety, J. Hadji-Lazaro, and C. Clerbaux, Service d'Aéronomie, Université Paris 6, 4, Place Jussieu, BP 102, 75252 Paris Cedex 05, France. (turquety@aero.jussieu.fr) 